PALLIC building relationships: One school's quest to raise Indigenous learners' literacy

Tasha Riley and Amanda Webster

Griffith Institute for Higher Research, Griffith University, Brisbane, Australia

Mt Gravatt campus, 176 Messines Ridge Road, Mt. Gravatt, Queensland 4122

t.riley@griffith.edu.au; a.webster@griffith.edu.au 


\title{
Principals as literacy leaders with Indigenous communities (PALLIC) building relationships: One school's quest to raise Indigenous learners' literacy
}

\begin{abstract}
In 2011 to 2012, 48 schools in the Northern Territory, South Australia and Queensland participated in the Principals as Literacy Leaders with Indigenous Communities (PALLIC) project. Central to this project was the establishment of positive working relationships between school principals and Indigenous community leaders in order to improve Indigenous literacy rates. Professional development in leadership skills and effective literacy instruction was provided through five professional learning modules. Participants worked together to create an action plan to support the literacy achievement of Indigenous students in their schools and communities. This article presents a case study of one participating school in Northern Queensland that successfully utilised the PALLIC framework to facilitate leadership actions and activities between Indigenous community and school leaders in order to form productive partnerships for the teaching of reading. In particular, the case study highlights the way that school leaders and Indigenous leaders established shared leadership and shared ways of learning in the school for reading outcomes of Indigenous students.
\end{abstract}


Despite general gains in areas of literacy and numeracy, a gap continues to exist between the achievement of Aboriginal and Torres Strait Islander students and other students in the Australian educational system (Commonwealth of Australia, 2015; Department of Employment, Education and Training, 2006; Gray \& Beresford, 2008; Harper et al., 2012; Klenowski, 2009; MCEECDYA, 2010). This gap has recently been highlighted in reports of national achievement measures such as NAPLAN. Klenowski (2009) has stressed that data indicate the gap widens as children progress from Years 3 to 7 . It can be argued that more attention should be focused upon the development and delivery of quality educational programs that are relevant to Aboriginal and Torres Strait Islander students and that enable high levels of achievement in reading and literacy skills. Without the identification of strategies that specifically address the literacy needs of Aboriginal and Torres Strait Islander students, this gap may continue to grow.

Researchers have acknowledged the potential benefits of parental engagement on learner achievement (Durand, 2011; Fluckiger, Jones, \& Diamond, 2012; Henderson, Jacob, Kernan-Schloss, \& Raimondo, 2004). Current research also indicates that parent-school partnerships can have a positive influence upon students' learning outcomes (Jeynes, 2012). Establishing meaningful partnerships between communities and schools takes time and effort (Mutch \& Collins, 2012; deFur, 2012). The Principals as Literacy Leaders with Indigenous Communities (PALLIC) project (Johnson, Dempster, McKenzie, Klieve Fluckiger, Lovett, Riley \& Webster, 2014) was developed in an attempt to improve the reading outcomes for all students at the school, but particularly focused on improvement of reading achievement for Indigenous students. Integral to the achievement of this aim is the participation of Indigenous community members in the critical leadership roles of Indigenous 
Leadership Partners (ILPs) to strengthen the bond between schools and families so that higher literacy outcomes amongst Aboriginal and Torres Strait Islander learners can be both achieved and maintained.

This article focuses upon one case study of a school located in rural Queensland. This school was selected because of the positive influence the PALLIC framework had upon facilitating collaboration for leadership actions and activities between ILPs and school leaders in order to form productive partnerships for the teaching of reading. Analysis of focus group interviews is provided in relation to the benefits and challenges as well as the potential long-term effectiveness of these actions on raising student literacy. Observations are summarised and discussed in order to consider which aspects of the initiative require further research and development.

Aboriginal scholar Karen Martin (2003) notes that the act of locating one's self within research enables others to determine both the "assumptions upon which [the research] is formulated and conducted" as well as "the types of relations that might exist” (p. 3). As two non-Indigenous researchers, we position ourselves within the research in an attempt to bridge the current divide between educators/researchers and Indigenous communities. In relation to the PALLIC project, we are part of a larger research team primarily located in Queensland, Australia. The first author is Canadian of European decent. Her research focuses on how teachers' expectations influence the opportunities afforded to Indigenous learners. Prior to her work as a researcher, she has worked as an education coordinator for a non-governmental community organisation and has experience teaching in a wide range of communities with a diverse group of learners. 
The second author identifies as American, originally from the Midwest region of the United States, with both European and Native American ancestors. Coming to Australia in 1998, she worked extensively with Indigenous children and families in the Northern Territory for 13 years in her roles as Early Intervention Advisor and school leader. Her current research focuses on the perspective of Indigenous families regarding support needed for their children with disabilities. We hope these details provide some context and understanding for the following perspectives shared.

\section{Background - Principals as Literacy Leaders with Indigenous Communities (PALLIC)}

Forty-eight schools, selected from across Queensland (22), South Australia (13) and the Northern Territory (13), were invited to participate in the PALLIC research project, based on the number of Indigenous students at their school and the poor achievement of these students on benchmark standards for reading. A significant number of children from these schools were identified as performing below National Minimum Standards for reading in Years 3, 5 and 7. Principals in the project were asked to identify one or two Indigenous community leaders who would advise as Indigenous Leadership Partners (ILPs) and who would be willing to work with the principals to develop and implement a literacy action plan for Indigenous students. Principals and ILPs initially participated in a series of professional development workshops in four key areas: characteristics of effective reading programs, links between leadership and learning outcomes, establishing shared leadership for learning through collaborative partnerships, and involving parents in literacy instruction. These workshops provided the skills and knowledge necessary for principals and ILPs to return to their schools and conduct an assessment of their school's leadership and 
literacy practices for Indigenous students before developing an action plan to address gaps for these students.

The PALLIC program aimed to determine the influence that a shared model of leadership and targeted action plans developed around the PALLIC framework could have upon raising literacy rates for Indigenous students. Specifically, the following two research questions are addressed in this case study:

- What are the leadership capabilities and practices necessary to link the work of leadership teams to Indigenous student literacy learning and achievement?

- What actions do principals and leadership teams need to take to form productive partnerships with Indigenous school/community leaders, parents and families over the teaching of reading?

In the following section, a brief summary is presented of each of the four areas underpinning the PALLIC model.

\section{Characteristics of effective reading programs}

Over the past two decades, researchers (Department of Education, Science and Training, 2005; Louden et al., 2005; Rowe, 2005) have concluded that effective reading programs must include instruction in phonological awareness, letter-sound knowledge, vocabulary, comprehension, and fluency. More recently, researchers (Peltier, 2010) concluded that oral language also is essential to reading instruction, particularly for Indigenous students who may come from different oral language backgrounds. Together, these six elements have been designated as the "BIG 6" of reading programs, which must all be included in reading programs leading to successful outcomes for students. In addition, the BIG 6 have also been established as comprising critical components of reading programs for Indigenous students and students from ESL backgrounds (Wheldall \& Beaman, 2000; Woolley, 2010). 
School principals and ILPs involved in the PALLIC project were asked to use a literacy practices guide to evaluate their current school practices against the evidence base of effective reading instruction, and to reflect on their use of data to assess student achievement against each of the areas of the BIG 6 as well as in overall reading outcomes. In addition, in keeping with research on effective reading programs for Indigenous students that indicates that instruction must address specific "ways of working and learning” (Frawley \& Fasoli, 2012; Fluckiger et al., 2012), educators were encouraged to assess their current use of practices such as storytelling, incorporation of visual images and symbols, and building links between classroom concepts and students' knowledge of alternative literacies and experiences related to the land, community, and culture within their reading programs (Rennie, 2006; Somerville, 2007).

\section{Leadership for learning outcomes}

The second key component of the PALLIC model was for school leaders to establish core practices in order to achieve positive student outcomes. Researchers (Dempster, 2009; Fletcher, Greenwood, Grimley, \& Parkhill, 2011; Jacobson, 2011) suggest that school leaders who develop school communities in which students achieve desired outcomes undergo a systematic process and address five key areas: professional development, shared leadership, conditions for learning, parent and community support, and curriculum and teaching. The element of shared leadership was especially critical for PALLIC as research on outcomes for Indigenous students (Frawley \& Fasoli, 2012; Fluckiger et al., 2012) indicates that involving community leaders is essential to the achievement in reading for Indigenous students. In addition, it is essential that school leaders establish a shared moral purpose around literacy, and specifically regarding reading achievement for some Indigenous students who may be 
achieving below benchmark standards. Effective school leaders are knowledgeable about the evidence base regarding literacy and reading achievement, and use a specific structure for discussions, known as “disciplined dialogue,” in which they use data to guide their questions and examination of practices and outcomes. Together, these elements (i.e., shared moral purpose, disciplined dialogue, five key areas) form a "Leadership Blueprint” (Dempster, 2009) in which school leaders can advance outcomes for students.

\section{Shared leadership through collaborative partnerships}

Some researchers (Frawley \& Fasoli, 2012; Mutch \& Collins, 2012) suggest that one way to close the literacy gap is to establish and build strong partnerships between schools and Indigenous communities. The Ministerial Council for Education, Early Childhood Development and Youth Affairs' Education Action Plan (MCEECDYA, 2010) acknowledges that:

Schools and early childhood education providers that work in partnership with families and communities can better support the education of Aboriginal and Torres Strait Islander children. These partnerships can establish a collective commitment to hold high expectations of Aboriginal and Torres Strait Islander children and young people and foster learning environments that are culturally safe and supportive. (p. 14)

Yet effective partnerships require intention, deliberation, a common goal, and a clear understanding of the roles and responsibilities of each partner in reaching that goal, none of which can be accomplished without the underlying foundation of trust and reciprocity (deFur, 2012). In Indigenous methodologies, the “four Rs” of respect, relevance, reciprocity, and responsibility (Kirkness \& Barnhardt, 1991) provide strong guiding principles for collaborative and community-based research (Battiste, Bell, \& Findlay, 2002; Gardner, 2000; Pidgeon \& Cox, 2002; Styres, Zinga, Bennett, \& Bomberry, 2010). Within this framework, the concept of reciprocity goes beyond 
the philanthropic notion of "giving back" (i.e., the university professor who creates a scholarship fund for high-achieving students attending her alma mater). Rather, it describes the critical transition that occurs when there is a shift away from "the role dichotomy between the producers and the consumers of knowledge in university settings” (Kirkness \& Barnhardt, 1991, p. 12) and a move towards shared meaning making and knowledge building that is embedded in daily practice. When reciprocity is applied within a research context, Pidgeon and Cox (2002) state that, "[it] entails honoring each other's roles” through clear expectations, well-defined group responsibilities, and “a balance of sharing and gathering information” to ensure mutual respect (p. 103).

While elements of trust and reciprocity are crucial when working with Indigenous communities, they are not commonplace in research contexts because, as Pidgeon and Cox (2002) have also argued, while "political correctness and revised ethical guidelines have attempted to protect the rights of minority groups [...] misplaced research practices have discouraged many Aboriginal groups from becoming willing participants” (p. 96). Since Indigenous and non-Indigenous researchers (Battiste et al., 2002; Battiste \& Youngblood Henderson, 2000; Dei, Hall, \& Rosenberg, 2000; Fredericks, 2007; Fredericks, 2008; Menzies, 2001; Minniecon, Franks, \& Heffernan, 2007; Smith, 1999; Styres et al., 2010) have exposed the negative experiences that certain research and educational processes have had on Indigenous communities, more emphasis has been placed on the need for collaboration between Indigenous communities and educational institutions. Researchers also caution that the concept of collaboration risks becoming little more than a tokenistic gesture if a clear articulation of shared goals is not made at the outset of the project, and efforts to undermine underlying power differences are not carefully 
applied (Mutch \& Collins, 2012; Riley, 2014). Without trust and reciprocity, meaningful collaborative partnerships cannot be created, particularly if community concerns regarding undesirable outcomes of collaborative projects are overlooked because of the assumed, but nominal, involvement of community members in the process. With this in mind, it was the aim of the PALLIC project to develop partnerships in which each party had a meaningful role in a reciprocal collaboration where trust was developed and extended beyond principals and schools to ILPs and communities.

In order to ensure collaborative leadership partnerships are effective and reciprocal, care must be taken to ensure that aims and goals are mutually beneficial (deFur, 2012; Gardner, 2000; Moreton-Robinson \& Walter, 2011; Styres et al., 2010). The concept of learning “both ways” (Frawley \& Fasoli, 2012; Ober \& Bat, 2007) is an Aboriginal Australian notion that describes the necessity for a shared approach to education and learning. Both ways learning anticipates that all partners have something of value to offer and learn from the other (Frawley \& Fasoli, 2012). Examples of both ways learning within an educational context include program development to ensure Indigenous staff and school principals work together in leadership roles within schools and engage in mutual learning and teaching, so as to create a shared sense of identity and purpose between school staff and community members (deFur, 2012; Mutch \& Collins, 2012). The PALLIC project attempts to facilitate both ways learning in order to reach the end goal of high literacy achievement by ensuring that school and community members work towards mutually agreed goals related to literacy achievement for Indigenous students, building on a foundation of reciprocal trust and equitable distribution of roles. A key part of these 
goals also focuses on facilitating the involvement of families in addressing literacy instruction for Aboriginal and Torres Strait Islander students.

\section{Parental involvement and literacy achievement}

Research demonstrates that parental involvement in education is related to higher student outcomes (Durand, 2011; Henderson et al., 2004; Huang, 2013; Jasinski, 2012; Williams, Sanchez, \& Hunnell, 2011). It may also alleviate the negative influence of poverty on learner achievement (Bolivar \& Chrispeels, 2011; Mutch \& Collins, 2012). Unfortunately, not all parents and guardians have the resources and/or confidence in their abilities to assist with their child's literacy learning. Bolivar and Chrispeels argue that some families, divested of the confidence that social and/or cultural capital can often cultivate, may be more reluctant to take collective action to demand the resources, skills, and training that would ensure their children's literacy success, despite a strong desire to do so.

However, research also confirms that, "the majority of parents care about their children's education and, with encouragement, will enter into productive partnerships with schools to lift achievement levels” (Mutch \& Collins, 2012, p. 173). Studies indicate that partnership programs that equip parents and guardians with the skills to facilitate their child's learning can have an equally positive influence on achievement (Freeman \& Bochner, 2008). For example, Jeynes’ (2012) meta-analysis of the efficacy of 51 different types of parental involvement programs found such programs were associated with statistically significant levels of higher academic achievement, while Huang's (2013) research found that a school-parent program using "literacy bags” (take-home packages of English reading and extension exercises) increased parents and guardians' understanding of and motivation regarding learners' language and reading acquisition. When well executed, partnerships between schools and 
communities provide parents and guardians with the skills and confidence to effectively engage with teachers in school and to work independently with their children at home. In return, school educators have the potential to gain a deeper understanding of the communities of all their learners, providing greater opportunities for more relevant learning.

While parent-school partnerships have been credited with the achievement of positive outcomes, ensuring such partnerships are sustainable requires time, patience and funding. Mutch and Collins (2012) note that the "extent to which parents become involved is influenced by their own schooling experiences and their perception of the school's culture and willingness to accept their contributions non-judgementally” (p. 174). Fluckiger et al. (2012) observe that, "in many family-school interactions, the strengths of Aboriginal and Torres Strait Islander parents and their communities are often overlooked and undervalued" (p. 58). They go on to note that programs such as PaL and Mums and Bubs in the Northern Territory, Australia, are an indication of the potential of community-school partnerships when "characterised by trust and mutual respect” (p. 58). PALLIC attempts to develop a similar bond between schools, communities and families by ensuring that principals and ILPs facilitate parental involvement and partnerships in developing and implementing strategies to raise student literacy achievement levels.

\section{Method}

The research phase of the PALLIC project was implemented over the course of one year across a number of schools in Queensland, South Australia and the Northern Territory. During the course of the project, multiple means of data collection were undertaken, including surveys, case studies, and interviews with key personnel. The case study data collection took place in seven schools from across the three 
government jurisdictions between the period of mid-September and mid-November 2012. A case study is a detailed study of a bounded system using in-depth data collection from multiple sources of information (Creswell, 2007). The case study was selected because it provided an opportunity to conduct in-depth interviews in focus groups and examine the action plans developed by the members of the school teams. In addition, the case study allowed for an exploration of the specific context of the school in order to gain a more multilayered description and use of data that could be interpreted against the backdrop of the literature. Schools were selected for case studies based upon their progress regarding building leadership partnerships and on reading outcomes with Indigenous children.

The case presented here is an urban, co-educational government primary school in rural Queensland. This school was particularly effective in adapting the PALLIC framework as a tool to assist, develop, and maintain a strong collaborative relationship between two Indigenous staff members, the school principal, and the school leadership team who acted as shared leaders for literacy initiatives for Indigenous students within the school community. The student body has an enrolment of approximately 660 students. Of the student body, 31\% (200) of the students identified as Indigenous, with 60\% of these students identifying as Aboriginal, 25\% as Torres Strait Islander, and $15 \%$ as both. The school has a high student mobility rate with a number of students moving in and out of school on a regular basis. To address the needs of this transient population of students and their families, the school employs a part-time mobility teacher. Records indicated that only $1 \%$ of the student body stated that English was their second language; however, accurate information regarding the language background of Indigenous students is difficult to retrieve due to a lack of recognition of Indigenous English dialects. Both the principal and ILPs 
reported that contrary to official documents, a number of the Indigenous learners attending the school were speakers of Aboriginal English and Creole.

In order to determine the effectiveness of PALLIC project in facilitating leadership practices that could positively influence Indigenous students' reading outcomes, interviews were held with the following five focus groups:

a) School leadership team composed of 10 people;

b) Junior primary teaching group composed of six teachers;

c) Upper primary teaching group composed of six teachers;

d) Parent group composed of two parents and two ILPs; and

e) ILP group composed of two ILPs and the school principal.

All five focus group interviews were conducted in a quiet staff room and were recorded for later transcription. In each focus group, one researcher took field notes while the other asked questions. Immediately after each conversation, the researcher provided the participants with a verbal summation of the interview to ensure accuracy. Later, all groups received a written transcript and were invited to make any necessary revisions. ILPs were members of school staff. One ILP was a literacy teacher and one was in the position of Community Liaison Officer.

The school principal invited the ILPs to sit in on all focus group discussions as ILPs were identified as having an essential and integral role in PALLIC. The participation of ILPs was regarded as vital to the school leadership team as well as to teaching groups and parent partnerships. In return, the ILPs extended an offer to the principal to join the ILP focus group. The aim of the focus group interviews was to determine if, and if so, how, the school principal and ILPs had created a collaborative partnership that successfully engaged parents and community towards the development and implementation of an action plan that increased Indigenous 
students' literacy skills. Teachers and ILPs were invited to share the practices they had undertaken as a result of their involvement in PALLIC and discuss the overall influence these practices had had upon reading levels, particularly for Indigenous learners.

Prior to the focus group interviews, the school principal and ILPs shared the literacy action plan they had developed and implemented for a period of 10 months as a part of the PALLIC project. The school elected to measure improvement in students' reading levels through the use of the NAPLAN reading subtest and PAT-R standardised assessments. Several priorities were identified for action by the school leadership team in order to increase Indigenous students’ reading levels. The priorities established by the school for PALLIC were as follows:

- Identify Aboriginal and Torres Strait Islander students who are ESL speakers and assist class teachers to establish individualised learning programs for them;

- Implement a whole-school reading program based on the BIG 6 and achieve consistency of teacher practice in the teaching of reading in all classrooms;

- Refine the school's whole-school Assessment and Reporting Framework informed by the BIG 6;

- Embed Aboriginal and Torres Strait Islander perspectives in school practices for all staff;

- Develop the active engagement and shared leadership of principals and ILPs in supporting reading achievement of Indigenous students; and

- Develop and implement a coaching and feedback program for staff in regards to reading and literacy instruction.

Although not specifically a direct part of the action plan, a significant objective and achievement was that ILPs also worked to maintain regular meetings with the Indigenous parent reference group.

Using thematic inquiry (Boyatzis, 1998), the final transcripts of the focus group interviews were read and re-read for emergent themes and individual concepts related 
to the literature review and over-arching research questions. The researchers strived to gain a more holistic understanding of each focus group's interpretations and observations by adding themes and sub-themes during the process of analysis. The connections noted between and across interviews helped to examine pre-conceptions and assumptions. Once themes were identified, they were coded, processed, and cross-checked by each author. A strict guideline was created to ensure the relevance of the themes and codes identified as well as the legitimacy of their application to the findings. A list adapted from Boyatzis and outlined by Rubin and Rubin (2005) was created to develop ways of recognising and labelling each concept.

\section{Results}

An analysis of focus group interviews revealed four themes: (1) shared, active, and both-ways leadership, (2) school-community relationships, (3) language and literacy learning, and (4) increasing student attendance, as significant actions supporting literacy and leadership that stem from PALLIC-related initiatives. Despite acknowledged difficulties around literacy, student mobility and absenteeism, the school has made considerable effort to promote PALLIC's blueprint of distributed leadership as a way to facilitate children's reading levels. Since the introduction of PALLIC, the school has reported positive outcomes such as improvement in the school's NAPLAN reading subtest scores. Baseline reading levels were obtained from NAPLAN reading tests administered just prior to the implementation of the PALLIC action plan. The tests were administered again approximately seven months after the commencement of the PALLIC project at the school. All students, except a small proportion $(<1 \%)$ who did not meet minimum requirements for spoken English, participated in NAPLAN testing. While determining the direct influence of PALLIC upon the improvement of these results is beyond the scope of this article, participants 
in all five focus groups reported PALLIC-related actions and activities were linked to the improvement of reading levels for students within the school.

\section{Shared, active, and both-ways leadership}

Several researchers (Bazylak, 2002; Hampton \& Roy, 2002; Malatest, 2004) have discussed the importance of establishing clear goals and benchmarks for ensuring the success of Indigenous learners. The principal created a distributed leadership team of varying strengths and skills who were willing to work collaboratively around priority areas including literacy, student mobility and absenteeism, and to link students' use of language and cultural understandings to literacy instruction. Rennie (2006) outlines cultural understandings or "literacies” as a key aspect of approaching literacy from a socio-cultural perspective in which consideration is given to the ways in which Indigenous learners utilise storytelling and literate practices within their communities. Some examples of these cultural literacies include those in which the individual is connected to their land, previous generations, cultural expectations, and teaching and learning.

The leadership team included the principal and key representatives of teaching and executive staff as well as two positions created from alternative funding - a Community Education Officer and a Mobility Officer - and the two ILPs. This leadership team met once a month to discuss PALLIC-related issues. The principal also organised a professional development day for staff on BIG 6 reading instruction and strategies, during which teachers were requested to plan a weekly balanced reading program to ensure they incorporated all elements of the BIG 6. One teacher reflected:

We had to sit down with our planning and think about things that we're doing in the classroom and what area of the BIG 6 that's being focused on, and to make sure that we're having a holistic approach to teaching reading, not just focusing on one area. So I guess that was a bit of an eye-opener when you sat 
down and looked at that. (Lower Primary Focus Group)

Teachers reported that the principal acted as a guide and mentor to empower teachers and ILPs to establish clear short- and long-term goals for reading programs and outcomes that were then shared with students and families. The principal was praised by teachers as being, “approachable and very structured in a good way”, illustrating a model of shared leadership that enabled teachers, ILPs and students to work towards a shared moral purpose (Dempster, 2009).

Along with shared leadership and the ability to maintain a focus on classroom reading instruction, PALLIC also attempts to facilitate "learning both ways" by encouraging teachers, staff, and ILPs to consider and build on the knowledge and experience regarding cultural literacies that families and students have to share. For example, the principal credited her multiple interactions with ILPs and the parent reference group for highlighting the value of embedding Indigenous perspectives throughout the school. She stated,

Our Indigenous parent reference group provide us with feedback around what we're doing. So, for example, at our meeting last week we talked about the new curriculum, the Australian curriculum, and the fact that this year there's been a lot of texts that have been introduced into the school that cover issues of interest and represent Aboriginal and Torres Strait Islander people, and we’ve been very interested in garnering their support and comment around, "Are these texts appropriate?”, "Do we need to contact families and talk about this before the children see them?” [ILP name] actually rang parents of every Aboriginal and Torres Strait Island child in the school to say, "We're about to use a text that deals with the stolen generation. Is this okay?” And I think that was a really useful process and parents are really appreciative, but we thought that perhaps we could be a bit more proactive next year and actually get parents in and show them at the beginning of year the range of texts, particularly of history.

Recognising the expertise and knowledge parents and ILPs bring into classrooms, the principal established bi-weekly meetings with ILPs to help strengthen the connections between the school and greater community as well as to address specific issues of interest and concern for Aboriginal and/or Torres Strait Islander learners. 
Specifically noted was how ILPs demonstrated to the leadership team that even small changes in practice make significant differences in terms of on-going issues such as absenteeism. ILPs were credited for encouraging the principal and teachers to come out of their classrooms and into the schoolyards to "meet and greet" parents and guardians before and after school as a way of enhancing community-school relationships. The principal acknowledged that this small change in behaviour seemed to have a positive influence on student attendance.

Other ideas credited to ILPs was the creation of the "text book scheme” enabling parents/guardians to have a loan on textbooks that they pay for gradually throughout the year and a "school starter pack" for students who may not have access to basic school supplies. Additionally, ILPs established a parent reference group where ILPs, school staff and parents could discuss PALLIC and reading strategies and consider practical ways to engage parents in reading. The development of fridge magnets providing families with "reading tips” was one strategy developed by the parent reference group that was thought to be especially successful with parents. One of the most significant aspects of PALLIC reported by teachers and school leaders was the positioning of the ILPs as experts and school leaders valued for their knowledge of Indigenous family perspectives and cultural knowledge. One of the ILPs noted that teachers now came to her for advice regarding how to embed Indigenous perspectives into the classroom. She stated,

Teachers are coming more to me because there's the Aboriginal and Torres Strait Islander perspective, and because we're embedding it, they're coming to me for more information and confirmation of stuff as well, and they're asking for community contacts, you know, can you get someone to come and do this, or, I actually managed to get some ochre into the school so the kids could actually see it in its natural form. So, I mean that's not an easy feat, but I managed to do it. So they're actually coming for more support.

Teachers confirmed that since the introduction of the ILPs there had been more time 
devoted to professional development for all staff on embedding Aboriginal and Torres Strait Islander perspectives in school (EATSIPS). Additionally, staff had credited ILPs with increasing their knowledge of Aboriginal English and Creole and the ways they could help students code-switch with Standard Australian English.

Similarly, ILPs described the importance of the PALLIC project in supporting them as emerging school leaders by saying that PALLIC has enabled them to "pick up their game" in developing a leadership presence within the school and community. The ILPs also suggested that PALLIC helped to strengthen their role within the school, stating that teachers, learners, and community members were now more likely to "see Indigenous leaders as just as important as the principal” (ILP 1). One ILP reported initially feeling apprehensive about presenting to larger groups but noted that, since her involvement in PALLIC, she has presented to a group of over 50 teachers. She also acknowledged being increasingly vocal with her ideas and opinions in school meetings. The ILPs stated that the principal's self-awareness and willingness to accept critical feedback gave them confidence that their ideas and opinions would be considered and respected. In addition, attending the workshops with the principal developed and strengthened ILPs relationship and roles within the school community. ILPs reported having a strong say within the leadership team in terms of both developing school and community partnerships and raising awareness of the cultural and linguistic factors influencing the literacy instruction for Indigenous students.

\section{School-community relationships}

Focus groups revealed that the stronger school-community relationships developed through the PALLIC project contributed to an educational environment conducive to raising the literacy rates of Aboriginal and Torres Strait Islander learners. The 
introduction of PALLIC ideals created a strong foundation for communication since teachers, ILPs, and parents had a common language for discussing literacy and language acquisition. One teacher noted,

I made the parents aware of the child's reading goals so that they have got the goal at home in their homework book as well. [...] So I get to see them [the parents] outside, and ask, “Are they reading every night?” and they'll come in and share what they're doing at home, and if they're struggling to get them to read. So I can follow-up at school, so we have a little bit more contact with parents I guess, face-to-face in lower school. (Upper Primary Teacher Focus Group)

ILPs also reported relaying PALLIC-related reading strategies to the parent reference group so that methods employed in the classroom could also be supported at home.

The creation of the ILP positions meant that families had an additional resource through which they could provide feedback, ask questions, and offer suggestions to the school. Parents reported that some families felt more comfortable raising school issues with the ILPs than they did discussing these issues with their child's teacher, because they felt the ILPs had a better understanding of Indigenous communities. Parents also commended ILP initiated strategies such as the yarning circles with students and reading resource workshops.

Responses from both the upper and junior primary teacher focus groups also revealed a strong appreciation for ILPs who were credited for enhancing their relationships with Aboriginal and Torres Strait Islander learners and their families. Teachers relayed that conversations with Aboriginal and Torres Strait Island students had become richer as a result of their interactions with ILPs since the ILPs provided a stronger understanding and appreciation of the differences in cultural understanding and literacies between non-Aboriginal and Torres Strait Islander peoples and Aboriginal and Torres Strait Islander peoples and also between different Aboriginal and Torres Strait Islander groups. The following two reflections illustrate this point: 
For me, I guess I've had someone to go to. I've got quite a few Indigenous kids in my class with a range of abilities and I'll just go to [ILP], "I've got this student, how would I do this?” or "can you help me out” and [ILP] had always given me really good advice. (Lower Primary Focus Group)

[The ILPs] took us to [museum name] and I think it was where it hit me the most - just understanding their [Aboriginal and Torres Strait Islander] cultural background and things that happened that was never taught to me - I guess I live in my own bubble to some degree and it was a real eye-opener. [...] It really has opened my eyes and given me more of an understanding. (Lower Primary Focus Group)

While the ILPs' efforts to facilitate partnerships between community members, families, and teachers appeared to result in increased understanding and engagement, some concern was expressed regarding teachers' overreliance on ILPs to communicate and collaborate with families. Although teachers acknowledged an increased effort to facilitate community/teacher relationships through school events, teachers noted continued difficulties with getting Aboriginal and Torres Strait Islander parents/guardians to engage with classroom and school activities. Teachers speculated that this could be due to parents'/guardians' embarrassment, apprehension, lack of time, or lack of comfort in relation to coming to school. In contrast, parent focus group responses revealed that parents wanted to see increased effort from teachers to work towards establishing community connections in alternative venues outside of school and to not overly depend upon ILPs for information and family contact, as noted in the following two statements:

I would say, “well, why can't the teacher ring me?” or "why can’t the teacher say, 'Hey, can I make a time to see you?'” Where I know the other parents, our other Indigenous parents will accept [ILP 1] to be that intervener there. But as for myself and [Parent 2], yeah, I'd like to hear it, hear from the teachers more. (Parent 1, Parent Focus Group)

I think they [teachers] would more or less need to get to know the parents more. I'm not saying that they're going to have time to know every parent of their class, but just a bit more knowledge of that family background. (Parent 2, Parent Focus Group)

Parents suggested that, to build community relationships, “small steps make a 
difference”. Both parents and ILPs stressed that establishing strong relationships between teachers and community members was essential if student literacy gains were to be sustained. Although both teacher and parent focus groups revealed some remaining challenges regarding school-community relationships, members of each group agreed that they had made progress towards establishing a culture of shared partnerships between schools and communities which was a significant step in meeting the needs of Indigenous students and families.

\section{Language and literacy learning}

All focus groups indicated that raising literacy achievement levels was a priority and discussed various impacts of the PALLIC strategies on reading engagement and outcomes for Indigenous students. Teachers credited PALLIC and ILPs for providing them with a more nuanced understanding of the influence students' home language had upon their reading achievement, as expressed in the following two statements:

I've been more aware, been made more aware of the strategies to teach ESL learners. I was, yeah, that's really something where I've grown with all this, and I'm really now, really conscious of how I teach so I'm not talking so much [laughter]. There's more visual now. (Upper Primary Focus Group)

I was under the impression that they [Aboriginal and Torres Strait Islander learners] were speaking English but in their home language, it was broken English, I guess how, you know, the stereotypical Aussies would have slang or something like that, so understanding that that is a language - that it's a language which, while it's not written in a text book and you can't go to a class like I would go to learn Italian, it still a language and understanding that [...] yes, there's definitely more of an awareness about that, definitely, since that started. (Upper Primary Focus Group)

Teachers also credited the BIG 6 for providing a more comprehensive understanding of students' needs and objectives in literacy and for making it easier to obtain data on the reading level of learners. Teachers and ILPs observed that using BIG 6 strategies assisted in increasing students' vocabulary and comprehension and reported that students were now focused on personal reading goals and making a concerted effort to 
reach those goals:

Yeah, well the kids have reading goals in every classroom, so each child in the school have their own reading goals, and it's on display as well. So the children are aware of where they're sitting and where they need to reach. So they set goals and try to reach their goal. So I guess that's helping with everything as well. (ILP focus group)

It [reading goals] seems to be something that the children want to achieve. [...] When they do achieve it, a big deal is made out of it. They're all ready to set themselves a new one. They're really focused. (Junior Primary Focus Group)

In the parent focus group, one ILP relayed how a student's reading level increased from Level 12 to Level 19 after using BIG 6 reading strategies first in school sessions and then in home sessions with the parent. The ILP reflected:

[Child's name] came to the Wave 3 Intervention twice a week and did some reading one-on-one [...]but that was at the start of the year. [...] When they've finished the program, I monitor their reading to see how they're going. So when [child's name] came to the program, she was reading at a Level 12 and when she finished the program she was Level 14, so she moved two levels. But in Term 3, this term, I went to monitor and do a reading and see where she was. Anyway, I couldn't believe; we got to Level 19! So she shifted to a Level 19 without any one-on-one support from us at school. And I said to [child's name], "Well, who’s been reading with you?” She said, "My mum”. (Parent Focus Group)

Parents and guardians attending the parent reference group were encouraged by the ILPs and the principal to share such narratives to inspire other parents and guardians to implement BIG 6 literacy learning strategies at home with their children.

Despite PALLIC’s positive influence on students’ literacy learning, upper primary teachers expressed some concern over the lack of appropriate resources for students in upper primary grades who are currently reading at lower levels:

But when you say “age related”, you've got Grade 7 kids reading a story about a rabbit; it'd be good if it was age related for them [...] It's a bit like, "I'm not a baby, because my younger sibling brought this home.” So that sort of thing. (Upper Primary Focus Group)

And for kids who don't move past one to five, then they're reading the same books every year. Like last year's teacher done [sic] them 10 times, and 
you've got to do them another 10 times. You're forever trying to find [ageappropriate books] on the Internet and do more ICT books and e-books, but it’s still difficult. (Upper Primary Focus Group)

Upper primary teachers also noted that in-class reading support from ILP literacy coaches was not as strong as it was for junior primary classes, although they did report that ILPs were helpful in assisting them to communicate and liaise with families.

\section{Student Attendance}

Another key theme of, and challenge to, increasing literacy levels of students identified by all five groups was student attendance. When asked about the various problems or challenges encountered in terms of engaging family and community, one ILP responded,

I think it's the attendance. Attendance is a big issue. I mean our kids come into the schools they're already behind because of the language barrier. And trying to get our kids to play catch-up, and doing that, you have to... we try to be very proactive in playing catch-up. (ILP 1, Parent Focus Group)

Focus group interviews revealed that strong community-school relations were believed to have the strongest influence upon deterring absenteeism. This moves away from the deficit discourse that perpetuates the notion that low attendance is a community issue as opposed to a shared responsibility. Advocated instead was a holistic approach towards the issue of absenteeism that emphasised the importance of relationship building. There was a shared understanding between all focus groups that if schools and classrooms were able to create welcome environments for students and the communities they represented while also providing clear-cut reasons as to why attendance was important, students would be more likely to come to class. As noted by one teacher:

You've got to have a really good relationship with the parents to, for them to get the student to school every day, so that's a great start. Once they get to school every day we can work with that and we can build on that. And for me, 
for my class just attendance has been really, really good but it takes a lot of people, including the parents to get them there and their mobility officer and everyone working in the background to get these kids to school. (Lower Primary Focus Group)

The importance of being "proactive” was recognised. Actions used by the school to ensure consistent attendance of students included: (a) clearly stated reasons within newsletters and assemblies as to why school attendance is important, (b) the inclusion of statistics to demonstrate the relation between attendance and academic outcomes, (c) home visits and text messages sent to parents and guardians regarding students' welfare and whereabouts, and (d) greeting students and their families before and after school each day. Most importantly, the school principal and leadership team had allocated funds to employ a mobility teacher to liaise with families and assist staff in developing new (and relevant) initiatives to address absenteeism. This was reported to have had some success in increasing attendance rates of some groups such as children of mobile families.

\section{Discussion}

Principals play a pivotal role in deciding whether or not meaningful communityschool partnerships are developed (Mutch \& Collins, 2012; Scanlan, 2011; TilleyLubbs, 2011). Scanlan (2011) argues that principals alone have the power to "structure school events in a manner that either promotes or inhibits school access to families” (p. 5). The principal in this study was not only deliberate in a focus on literacy achievement, but also made an effort to ensure Aboriginal and Torres Strait Islander culture and literacies were valued and promoted within school curriculum and pedagogy. The inclusion of two ILPs, whose advice and guidance regarding Indigenous and local community knowledge helped to shape professional development and classroom practice, assisted this process.

In turn, the ILPs acknowledged increased self-confidence, leadership skills, and 
leadership status within the school and the community as a result of collaborating with the principal and other school leaders throughout the PALLIC project. Having been provided with professional development on BIG 6 strategies, the ILPs reported feeling more confident in their ability to share literacy learning strategies with parents and guardians who could practise them at home with their children. Parent focus group responses also revealed that the creation of a parent group, combined with ILPs' increased leadership status within the school, meant parents felt more confidence both that their concerns and suggestions regarding classroom practice would be addressed, and in their own abilities to provide their children with literacy support. This is consistent with other research findings (Bolivar \& Chrispeels, 2011; Jeynes, 2012;Mutch \& Collins, 2012; Scanlan, 2011; Tilley-Lubbs, 2011) that demonstrate the positive influence parent groups have on increasing parents’ ability, confidence, and willingness to collaborate with school staff. Responses of the parent group also revealed that even small gestures such as the "meet and greet sessions" before and after school first instigated by the ILPs and then followed up by the principal and individual teachers, were reported to have a positive influence over attendance. Given the negative influence repeated school absences are reported to have on children' s literacy learning (Ehrich et al., 2010), this seemingly small gesture may result in students and families feeling more connected to school communities and thus having relatively large outcomes in terms of literacy achievement.

\section{Recommendations for Future Practice}

\section{Increased connections with community}

While it was noted that increased effort had been made by ILPs and school staff to create opportunities such as the parent reference group for parents and staff to come together, ILPs and parents agreed that still more effort was needed to ensure that (a) 
more Aboriginal and Torres Strait Islander peoples were recruited into teacher and leadership positions within the school, and (b) teachers took the initiative to find out more about the community and Indigenous literacies and teaching practices. Mutch and Collins (2012) claim that parents become more confident in engaging with teachers and classroom activities, “when teachers displayed a willingness to learn about the child's background and showed an interest in the child's particular needs and interests” (p. 180). Although parents initially appreciated the ILPs' bridging role between community and school, some parents were now interested in seeing teachers make the same effort to engage with the community. This desire was echoed by the ILPs who reported overall satisfaction with their role as school leaders, but also noted feeling increasingly fatigued. The ILPs shared that they often communicated with parents about classroom concerns until late in the evening. Teacher responses also revealed that teachers were heavily dependent upon ILPs to solve classroom or school yard dilemmas involving Aboriginal and Torres Strait Islander students before trying to sort out the issue themselves. Although ILPs acknowledged being happy to help support this process, both ILPs and parents noted that it would be more effective if teachers engaged directly with students and families rather than relying on an intermediary process. As Gardner (2000, p. 202) reminds us, when non-Indigenous people work together with Indigenous communities, the "reciprocal process requires collaboration and the ability to learn from the tensions inherent in bringing different approaches and contents together” (p. 202). Teachers committed to true reciprocal relationships with Indigenous communities will be the teachers who extend themselves beyond classroom barriers to engage in shared dialogues in environments where Indigenous communities feel comfortable to speak openly and honestly. They will walk in knowing that there may be disagreements, that their ideas might be 
rejected, and that there will be confusion and misunderstandings along the way. However, they will also be prepared to listen, be flexible, and acknowledge when they may be wrong. Finally, the committed teacher will not be afraid to (respectfully) ask difficult questions and will be prepared to listen to the answers, because the committed teacher will know that it is through asking these questions, that the most meaningful learning occurs. Parents, ILPs and the principal agreed that while the support of ILPs was necessary, a true reciprocal relationship would only be possible if teachers were willing to engage, think outside of the box, and extend themselves beyond the boundaries of the classroom (Cherubini, 2011; Fluckiger et al., 2012; Mutch \& Collins, 2012).

\section{Lack of age-appropriate literacy resources for older students and attendance}

Another significant finding was the lack of appropriate resources and support for students in upper primary classrooms who were currently achieving well below benchmark standards in reading and literacy. The upper primary teachers noted that it was a struggle to keep older learners engaged in reading activities when the textbooks geared at their level were often not age appropriate and did not reflect the learners' age or interests. In addition, ILPs worked more with lower primary classes on reading and engaged more with upper primary classes on matters related to behaviour and wellbeing. This had the unintended result that teachers in upper primary classes were not as exposed to the perspectives and ideas related to language and literacy that the ILPs had shared with the lower primary teachers and students. This also meant that ILPs did not have as much communication specific to reading and literacy with the parents and guardians of upper primary students, and were not able to provide parents with much guidance or support in implementing reading activities within the home setting. Since research (Freeman \& Bochner, 2008) indicates that parents’ interaction 
with children around reading at home can have a significant impact on reading achievement for students, this is an important gap that needs to be addressed.

\section{Student Attendance}

Finally, teachers, school leaders and ILPs all mentioned that attendance continued to be a challenge in improving literacy outcomes. Although the school had made a concerted effort in allocating resources and personnel to improve attendance, staff still mentioned that many students continued to miss a fair number of days due to family issues or illness. Constructive dialogue and collaboration between school staff and families is critical if this particular challenge is to be adequately addressed (Ehrich et al., 2010). The perspectives of families need to be considered if attendance initiatives are to build on core beliefs and value systems of Indigenous families regarding school and reading instruction (Shipp, 2012).

\section{Limitations}

The PALLIC project was initiated with the premise that systematic change must be driven by a shared model of leadership in order to effect school-wide implementation of reading strategies leading to increased achievement of Indigenous students. It must be acknowledged, however, that the full impact of this approach on systematic change at a school level was not able to be determined due to the limited time of the project. In addition, the main focus of the PALLIC project and the case study reported in this article was on reading achievement, which is only one aspect of literacy achievement. Further research is needed to explore the types of systematic change that is required to enable Indigenous learners to develop their own traditional literacies and knowledge while also supporting complete engagement in school literacy programs. As suggested by McNaughton and Lai (2009), school leaders need to explore ways to challenge traditional learning methods and build communities of practice that engage in 
effective problem solving for the literacy learning and achievement of Indigenous students.

\section{Conclusion}

After examining and completing analysis of the reports of focus groups and data provided by the school on literacy achievement, evidence from this case study reveals that PALLIC was viewed as a success within the school for the program's ability to facilitate meaningful both-ways relationships between school leaders and ILPs. Ongoing collaboration between leadership team members, and recognition and validation within the school of ILPs as experts on Indigenous knowledge and literacies, combined with professional development on implementation of the BIG 6 strategies within the classroom, were reported to help in strengthening the literacy achievement of Indigenous students within the school. The collaboration between ILPs and the parent group was regarded as one way of building trust between schools and community members. ILPs were able to act as a bridge from the community to the school and vice versa, since ILPs were well versed in the practices and policies of the school but also had the community connection and awareness, and so were able to "translate" the needs of one to the other. A stronger community/school partnership was seen as having a positive influence on Indigenous children’s learning and achievement in reading, as parents/guardians who could see that the school had a vested interest in ensuring Indigenous learner success were more inclined to work together with the school. Sharing narratives around Indigenous learners’ literacy success was regarded as a good motivator towards sustaining those relationships.

Despite the positive gains brought about by PALLIC-related strategies, increased effort is needed to ensure teachers do not become dependent upon ILPs for their work with Indigenous learners. In order for PALLIC strategies to maintain 
success, continuous effort needs to be made by teachers as well as ILPs in engaging with parents and communities to ensure true collaboration and partnerships. Equal investments of teachers, principals, and ILPs towards developing meaningful relationships with the community are necessary to ensure the gains made in Indigenous literacy rates are sustained. In addition, upper primary teachers and ILPs reported a need for more comprehensive supports and resources for older students who were struggling with basic skills in reading and literacy. Additional research should focus on meaningful supports and resources that can assist Indigenous students who are still struggling with reading in upper primary grades in order to ensure that they do not become unmotivated and disengaged. 


\section{References}

Battiste, M., Bell, L., \& Findlay, L.M. (2002). Decolonizing education in Canadian universities: An interdisciplinary, international, Indigenous research project. Canadian Journal of Native Education, 26(2), 82-95.

Battiste, M., \& Youngblood Henderson, J. Y. (2000). Protecting Indigenous knowledge and heritage: A global challenge. Saskatoon, SK: Purich.

Bazylak, D. (2002). Journeys to success: Perceptions of five female Aboriginal high school graduates. Canadian Journal of Native Education, 26(2), 134-151.

Bolívar, J.M., \& Chrispeels, J.H. (2011). Enhancing parent leadership through building social and intellectual capital. American Educational Research Journal, 48, 4-38. doi: 10.3102/0002831210366466

Boyatzis, R. E. (1998). Transforming qualitative information: Thematic analysis and code development. Thousand Oaks, CA: Sage.

Cherubini, L. (2011). Understanding the marginalized in the mainstream: Teacher education and Aboriginal educational policy in Ontario (Canada). International Journal of Education, 3(2), 1-21.

Commonwealth of Australia. (2015). Closing the Gap: Prime Minister's Report . Canberra: Commonwealth of Australia.

Creswell, J. (2007). Qualitative inquiry and research design: Choosing among five approaches (2nd ed.). Thousand Oaks, CA: Sage.

deFur, S. (2012). Parents as collaborators: Building partnerships with school- and community-based providers. Teaching Exceptional Children, 44, 58-67.

Dei, G. J. S., Hall, B., \&Rosenberg, G. (2000). Indigenous knowledges in global contexts: Multiple readings of our world. Toronto: University of Toronto Press. 
Dempster, N. (2009). Leadership for learning: A Framework synthesizing recent research. EdVentures.

Department of Education, Science and Training. (2005).Teaching Reading: Report and Recommendations. National Inquiry into the of literacy, Department of Education Science and Training, Canberra.

Department of Employment, Education and Training. (2006). Annual report 20052006 (pp. 1-5). Darwin, NT: Northern Territory Government.

Durand, T.M. (2011). Latino parental involvement in kindergarten: Findings from the early childhood longitudinal study. Hispanic Journal of Behavioral Sciences, 33, 469-489. doi: 10.1177/0739986311423077

Ehrich, J., Wolgemuth, J.R., Helmer, J., Oteng, G., Lea, T., Bartlett, C., ... Emmett, S. (2010). Attendance, performance and the acquisition of early literacy skills: A comparison of Indigenous and non-Indigenous school children. Australian Journal of Learning Difficulties, 15, 131-149. doi:

$10.1080 / 19404150903524580$

Fletcher, J., Greenwood, J., Grimley, M. \& Parkhill, F. (2011). Raising literacy achievement in reading: How principals of 10 to 12 year old students are making this happen. International Journal of Leadership in Education: Theory and Practice, 14(1), 61-83.

Fluckiger, B., Jones, W., \& Diamond, P. (2012). Yarning space: Leading literacy learning through family-school partnerships. Australasian Journal of Early Childhood, 37(3), 53-59.

Frawley, J., \& Fasoli, L. (2012). Working together: Intercultural leadership capabilities for both-ways education. School Leadership \& Management, 32, 309-320. 
Fredericks, B.(2008). Making an impact researching with Australian and Torres Strait Islander peoples. Studies in Learning, Evaluation, Innovation and Development. 5 (1): 24-35.

Fredricks, B.L. (2007). Utilising the concept of pathway as a framework for Indigneous research. Australian Journal of Indigenous Education. 36, 15-22.

Freeman, L., \& Bochner, S. (2008). Bridging the gap: Improving literacy outcomes for Indigenous students. Australian Journal of Early Childhood, 33, 9-16.

Gardner, E. (2000). First Nations house of learning: A continuity of transformation. In M.B. Castellano, L. Davis, \& L. Lahache (Eds), Aboriginal education: Fulfilling the promise (pp. ?-?). Vancouver: UBC Press.

Gray, J., \& Beresford, Q. (2008). A 'formidable challenge': Australia's quest for equity in Indigenous education. The Australian Journal of Education, , 52, 197-223.

Hampton, M., \& Roy, J. (2002). Strategies for facilitating success of First Nations students. The Canadian Journal of Higher Education, 32(3), 1-28.

Harper, H., Helmer, J., Lea, T., Chalkiti, K., Emmett, S., \& Wolgemuth, J.R. (2012). ABRACADABRA for magic under which conditions? Case studies of a webbased literacy intervention in the Northern Territory. The Australian Journal of Language and Literacy, , 35, 33-50.

Henderson, A., Jacob, B., Kernan-Schloss, A., \& Raimondo, B. (2004). The case for parent leadership. Prichard Committee for Academic Excellence. Arlington, VA: KSA Plus Communications.

Huang, S. (2013). The use of literacy bags promotes parental involvement in Chinese children's literacy learning in the English language. Language Teaching Research, 17, 251-268. doi: 10.1177/1362168813475950 
Jacobson, S. (2011). Leadership effects on student achievement and sustained school success. International Journal of Educational Management, 25, 33-44. doi: $10.1108 / 09513541111100107$

Jasinski, M. (2012). Helping children to learn at home: A family project to support young English-language learners. TESL Canada Journal, 29, 224-230.

Jeynes, W. (2012). A meta-analysis of the efficacy of different types of parental involvement programs for urban students. Urban Education, 47, 706-742. doi: $10.1177 / 0042085912445643$

Johnson, G., Dempster, N., McKenzie, L., Klieve, B., Fluckiger, B., Lovett, S, Riley, T. \& Webster, A. (2014). Principals as literacy leaders with Indigenous communities: Leadership for learning to read both ways. Kingston, ACT: Australian Primary Principals Association.

Kirkness, V., \& Barnhardt, R. (1991). The four Rs: Respect, relevance, reciprocity, and responsibility. Journal of American Indicant Education, 30, 1-15.

Klenowski, V. (2009). Australian Indigenous students: Addressing equity issues in assessment. Teaching Education, 20(1), 77-93. doi:

$10.1080 / 10476210802681741$

Louden, W., Rowe, K., Rohl, M., Barratt-Pugh, C., Brown, C., Cairney, T., ... Rivalland, J. (2005). Context for the study of effective literacy teaching practices in the early school years. The Australian Journal of Language and Literacy, 28, 183-184.

Malatest, R. A. (2004). Aboriginal peoples and postsecondary education. Montreal, Canada: Millennium Scholarship Foundation.

Martin, K. L. (2003). Ways of knowing, ways of being and ways of doing: A theoretical framework and methods for Indigenous re-search and indigenist 
research. Voicing Dissent, New Talents 21C: Next Generation Australian Studies Journal of Australian Studies, 76, 203-214.

Moreton-Robinson, A, Walter, M 2011, Leadership in Indigenous research capacity building: implementing and embedding an Indigenous research methodologies Master class module, Office for Learning and Teaching, Sydney, viewed 23 Mar 2015, http://www.voced.edu.au/content/ngv65107.

MCEECDYA. (2010). Aboriginal and Torres Strait Islander Education Action Plan 2010-2014. Carlton South, Victoria: MCEECDYA.

McNaughton, S., \& Lai, M. K. (2009). A model of school change for culturally and linguistically diverse students in New Zealand: A summary and evidence from systematic replication. Teaching Education, 20, 55-75. doi:10.1080/10476210802681733

Menzies, C. R. (2001). Reflections on research with, for, and among Indigenous peoples. Canadian Journal of Native Education, 25, 19-35.

Minniecon, D, Franks, N., \& Heffernan, M. (2007). Indigenous research: Three researchers reflect on their experiences at the interface. The Australian Journal of Indigenous Education, 36, 23-31.

Mutch, C., \& Collins, S. (2012). Partners in learning: Schools' engagement with parents, families, and communities in New Zealand. School Community Journal, 22, 167-187.

Ober, R., \& Bat, M. 2007. Paper 1: Both-ways: The philosophy. Ngoonjook: A Journal of Australian Indigenous Issues, 31(64), 86.

Peltier, S. (2010). Facilitating language and literacy learning for students with Aboriginal English dialects. Canadian Journal of Native Studies, 32, 114-155. 
Pidgeon, M., \& Cox, D. (2002). Researching with Aboriginal peoples: Practices and principles. Canadian Journal of Native Education, 26, 96-106.

Rennie, J. (2006). Meeting kids at the school gate: The literacy and numeracy practices of a remote Indigenous community. The Australian Educational Researcher, 33, 123-142.

Riley, T. (2014). Into the community and not on the shelf: Learning to develop meaningful HIV/AIDS curriculum for multiple communities. Sex Education: Sexuality, Society and Learning, 14(1), 42-56. doi: $10.1080 / 14681811.2013 .822363$

Rowe, K. (2005). Teaching reading: National Inquiry into the Teaching of Literacy Research Report. Canberra, Australia: Department of Education, Science and Training.

Rubin, H. J., \& Rubin, I. (2005). Qualitative interviewing: The art of hearing data. Thousand Oaks, Calif: Sage Publications.

Scanlan, M. (2011). How school leaders can accent inclusion for bilingual students, families, \& communities. Multicultural Education, 18(2), 5-9.

Shipp, C. (2012). Why indigenous perspectives in school?: A consideration of the current Australian education landscape and the ambiguities to be addressed in literacy teaching. English in Australia, 47, 20-24.

Smith, L. T. (1999). Decolonizing methodologies: Research and Indigenous peoples. New York: St. Martin’s Press.

Somerville, M. (2007). Place literacies. Australian Journal of Language and Literacy, 30, 149-164. 
Styres, S., Zinga, D., Bennett, S., \& Bomberry, M. (2010). Walking in two worlds: Engaging the space between Indigenous community and academia. Canadian Journal of Education, 33, 617-648.

Tilley-Lubbs, G. (2011). The power is in the partnership: Families as partners in bilingual bicultural family literacy programs. Creative Education, 2, 288-291. doi: 10.4236/ce.2011.23039

Wheldall, K., \& Beaman, R. (2010). 'Mind the gap': Effective literacy instruction for indigenous low-progress readers. The Australasian Journal of Special Education, 34, 1-16. doi:10.1375/ajse.34.1.1

Williams, T.T., Sánchez, B., \& Hunnell, J. (2011). Aligning theory with practice: Understanding school-family partnerships at an inner-city high school. Children and Youth Services Review, 33, 689-697. doi: 10.1016/j.childyouth.2010.11.012

Woolley, G. (2010). Issues in the identification and ongoing assessment of ESL students with reading difficulties for reading intervention. Australian Journal of Learning Difficulties, 15, 81-98. doi: 10.1080/19404150903524564 